\title{
Study on Cleaning Performance of Small Road Sweeper Vehicle
}

\author{
Qingliang Yang ${ }^{1}$, Yao Zhou ${ }^{1}$, Kaiming Ying ${ }^{1}$, Rongbin $\mathrm{Li}^{2}$ and Xin Wang ${ }^{2, *}$ \\ ${ }^{1}$ School of Materials Science and Engineering, Shanghai Dian Ji University, 1350 Ganlan Rd., Shanghai 201406, China \\ ${ }^{2}$ Institute of Energy Equipment Materials, Shanghai Dian Ji University, 1350 Ganlan Rd., Shanghai 201406, China \\ ${ }^{*}$ Corresponding author
}

\begin{abstract}
Taking the rubbish in the campus of Shanghai Electric Power University as the test object, the single-factor and three-factor five-level orthogonal test design methods were adopted to conduct an experimental study on the cleaning performance of the road cleaner cleaning system and obtain the optimal combination. The mathematical models of the three main factors of driving speed, disc brush speed and roller brush speed and the road sweep rate were established. The influence of each influencing factor and its interaction on the road sweep rate was analyzed, and parameters optimization and test verification were performed. The best combination was found to be a running speed cleaning speed of $5.27 \mathrm{~km} \cdot \mathrm{h}^{-1}$, a disk brush speed of $106.85 \mathrm{r} \cdot \mathrm{min}^{-1}$, a roller brush speed of $159.86 \mathrm{r} \cdot \mathrm{min}^{-1}$, and a road cleaning rate of $92.81 \%$. After the test is verified, it is basically consistent with the theoretical optimization results.
\end{abstract} vehicle

Keywords—sweeper rate; brush roller brush; road test; sweeper

\section{INTRODUCTION}

The increasing of the national sanitation requirements, as a road sweeper cleaning operation tool, its application in favour of small electric road cleaning vehicle is one kind of new environmental protection equipment to replace manual cleaning, and thought the manual cleaning to reduce the harm to health, reduce cleaning cost, improve the cleaning efficiency [1-5]. It uses mechanical cleaning, the cleaning, garbage collection, cleaning, transportation as a whole, fully solving the road of garbage collection, transportation, mainly for streets, schools, residential areas such as road pavement more complicated operation, solving the large sweeper leakage scanning problem, because of its small body size. The operation is very flexible [611]. At present, Taneda Y [12] found that for small inhaled sweeper with rolling brush cleaning effect simulation analysis, simulation analysis is carried out through the cleaning process for the two kinds of brush when the differences between the two: the spiral rolling lateral displacement increases obviously when the brush cleaning, the straight line sweeping on both sides is not balanced a straight line, spiral rolling brush cleaning effect is good. Yang Huiping [13] have designed the small sweeper for cleaning the road teeth. The purpose of the sweeper is not only to clean the road, but also to clean the vertical surface of the pavement. Huang Xinghua [14] carried out a single factor test on the cleaning vehicle cleaning device on the road simulation test platform, and the primary and secondary factors affecting brush speed and speed, roller brush speed and vehicle speed were obtained.
Therefore, the research group according to the design requirements and vehicle cleaning systems, the developments of a small road cleaning vehicle, road test was carried out on the campus of the Shanghai Dian Ji University and, by single factor test and orthogonal test method, the main parameters of road cleaning performance optimization[15], and provide a reference for the further optimization design of small road cleaning machine cleaning and road system of the cleaning rate of increase.

\section{EXPERIMENTAL MATERIALS AND METHOD}

\section{A. Test Equipment and Instruments}

The cleaning performance test is carried out using a selfmade small road cleaning machine, as shown in Figure I. It is mainly composed of frame, cleaning device, lifting device, steering system, vibration damper, walking wheel and motor, etc. The frame adopts steel rectangular thick $3 \mathrm{~mm}$ pipe material the bottom of the frame plate spring made of 45 steel materials; lifting device is arranged in the middle of the frame for cleaning device improvement; cleaning device is composed of a disc brush, roller brush component parts and a collecting box, placed between the frame at the bottom of the two wheels[16], as shown in Figure II. The other instruments include electric heat dryness box, tape measure, electronic digital vernier caliper, ACL-210.4 electronic balance (precision $0.001 \mathrm{~kg}$ ) and so on.

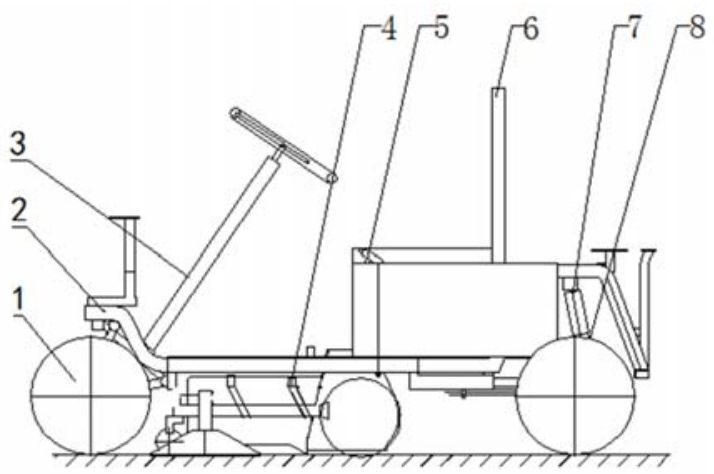

(1-WHEEL; 2-VEHICLE FRAME; 3-STEERING SYSTEM; 4-SWEEPER SYSTEM; 5-ROLLER SYSTEM; 6-SEATR; 7-SHOCK ABSORBER; 8 MOTOR)

FIGURE I. THE STRUCTURE SKETCH OF THE SMALL ROAD SWEEPER VEHICLE

B. Working Principle

The sweeper operating, disc brush collection box 3 on both 
sides of the 2 through the 1 disc brushless motor drive (Figure II), the corner or roadside garbage to brush work area 6 , rolling brush brush motor driven by 5 , and put the garbage on the ground, leaves, mud, gravel and other roll feeding to the collection box cleaning machine, cleaning device for lifting and lowering the operating handle by parallel four bar mechanisms.

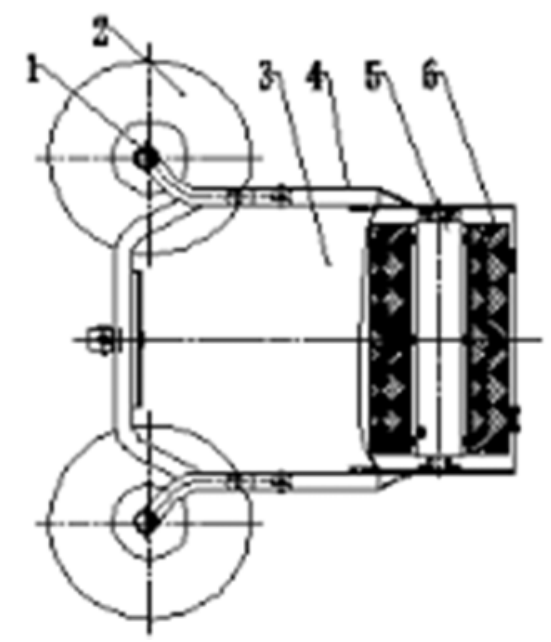

(1-BRUSH MOTOR; 2-BRUSH; 3-THE COLLECTION BOX; 4-THE ROLLING BRUSH BRACKET; 5-ROLLING BRUSH MOTOR, 6ROLLING BRUSH)

FIGURE II. THE SCHEMATIC DIAGRAM OF SWEEPER SYSTEM

\section{Experimental Materials}

The test materials are leaves, soil and stones on the campus of Shanghai Dian Ji University. The mean length of the leaf size measured by random sampling is $(69.20+10.36) \mathrm{mm}$, width $(45.66+8.62) \mathrm{mm}$, thickness $(0.29+0.07) \mathrm{mm}$, and the average diameter of the stone is $5.3 \mathrm{~mm}$. The moisture content of leaves was measured to be $(21.35+0.6) \%$ according to the national standard GB/T1 931-2009, and the soil moisture content was $(3.1+0.6) \%$ according to SL237-1 999, and the water content of stone was $(2.2+0.5) \%$. The test road is a smooth and solid cement pavement. The climate is in accordance with the GB/T 12534 standard, the weather is clear, the temperature is 30 , and the wind speed is $1.5 \mathrm{~m} / \mathrm{s}$.

\section{Experimental Index}

The road performance test of the cleaning machine is based on JB/T 7303-2007, and the cleaning rate is selected as the test index[17].

The cleaning machine was cleaned with its average garbage volume of $20 \mathrm{~g} / \mathrm{m} 2$ (garbage for leaves, stone and soil mixed). Its cleaning speed was measured at its rated speed. The cleanup rate was calculated by measuring the amount of ground rubbish before sweeping and the residual amount of ground garbage after cleaning, and got [18].

That is:

$$
\eta=\frac{W_{0}-W_{1}}{W_{0}} \times 100 \%
$$

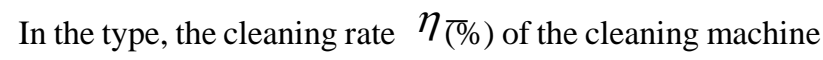
(\%); the total amount $W_{0}$ of the waste $(\mathrm{kg})$ in the test site, and the amount of garbage $W_{1}$ - collected after the cleaning (kg).

\section{E. Experimental Plan}

The experiment aims to explore the optimal combination of the improved small road cleaning machine to meet the requirements of all factors under the influence of multiple factors.

The three factor and five level orthogonal rotation center combination method were used in the experiment. The cleaning speed is selected as the test factor, and the cleaning rate is the test index. The influence of three test factors on the cleaning rate of test index is discussed, and the interaction between various factors is considered. According to the test results and theoretical analysis of the pretest, the range of the level of the test factors is determined. The test factor level code table is shown in Table I. The experiment was carried out in 23 groups. Each group was repeated 3 times. The length of the sample was $30 \mathrm{~m}$, and the width was $1 \mathrm{~m}$. The cleaning rate based on the formula (1) was calculated, and the mean value of the 3 test results was taken as the test result. The design of the test scheme and the result analysis are completed by Desigin Expert6.0.10 software.

TABLE I. EEXPERIENTAL FACTORS AND LEVELS

\begin{tabular}{|c|c|c|c|}
\hline \multirow[b]{2}{*}{$\begin{array}{l}\text { Coded } \\
\text { value }\end{array}$} & \multicolumn{3}{|c|}{ Factors } \\
\hline & $\begin{array}{c}\text { Driving speed } \\
\text { X } \\
\left(\mathrm{km} \cdot \mathrm{h}^{-1}\right)\end{array}$ & $\begin{array}{c}\text { Rotating speed } \\
\text { of disk brush } \\
\text { X2 } \\
\left(r \cdot \mathrm{min}^{-1)}\right.\end{array}$ & $\begin{array}{c}\text { Roller brush } \\
\text { speed } \\
\text { X3 } \\
\left(r \cdot \mathrm{min}^{-1}\right)\end{array}$ \\
\hline-1.682 & 3.0 & 90 & 100 \\
\hline-1 & 3.8 & 98 & 112 \\
\hline 0 & 5.0 & 110 & 130 \\
\hline 1 & 6.2 & 122 & 148 \\
\hline 1.682 & 7.0 & 130 & 160 \\
\hline
\end{tabular}

\section{RESULTS AND ANALYSIS}

\section{A. Experimental Results}

According to the experimental design scheme, the cleaning performance of the improved small road cleaning machine is tested, as shown in Figure III. X1, X2 and X3 are used to express the running speed of the cleaning machine, the speed of the disk brush and the rotational speed of the rolling brush. It is considered for the test index cleaning rate and the interaction of various factors. The test plans and results are shown in Table II.

\section{B. Regression Analysis}

1) Mathematical model and significance analysis:

The experimental design software Design Expert 6.0.10 is used to do multiple regression fitting [19] for the test results in Table II, and the regression equation of the sweep rate as the response function and the independent level of the influencing factors as the independent variable is obtained, which is shown in formula 2, and the significance is verified by the test. 


$$
\begin{aligned}
& y=88.35-0.46 X_{1}+0.77 X_{2}+2.28 X_{3} \\
& +0.38 X_{1}^{2}-0.80 X_{2}^{2}+0.22 X_{3}^{2} \\
& +0.13 X_{1} X_{\supset}+0.17 X_{1} X_{2}-0.73 X_{2} X_{2}
\end{aligned}
$$

In the formula, $X_{1} 、 X_{2} 、 X_{3}$ are coded for the level of

\begin{tabular}{|c|c|c|c|c|}
\hline No. & $X_{1}$ & $X_{2}$ & $X_{3}$ & Sweep rate(\%) $y_{i}$ \\
\hline 1 & -1 & -1 & -1 & 85.45 \\
\hline 2 & 1 & -1 & -1 & 83.05 \\
\hline 3 & -1 & 1 & -1 & 88.21 \\
\hline 4 & 1 & 1 & -1 & 87.58 \\
\hline 5 & -1 & -1 & 1 & 90.36 \\
\hline 6 & 1 & -1 & 1 & 89.88 \\
\hline 7 & -1 & 1 & 1 & 91.43 \\
\hline 8 & 1 & 1 & 1 & 90.23 \\
\hline 9 & -1.682 & 0 & 0 & 89.72 \\
\hline 10 & 1.682 & 0 & 0 & 88.75 \\
\hline 11 & 0 & -1.682 & 0 & 85.36 \\
\hline 12 & 0 & 1.682 & 0 & 86.43 \\
\hline 13 & 0 & 0 & -1.682 & 84.76 \\
\hline 14 & 0 & 0 & 1.682 & 92.81 \\
\hline 15 & 0 & 0 & 0 & 88.35 \\
\hline 16 & 0 & 0 & 0 & 88.98 \\
\hline 17 & 0 & 0 & 0 & 87.56 \\
\hline 18 & 0 & 0 & 0 & 87.98 \\
\hline 19 & 0 & 0 & 0 & 88.15 \\
\hline 20 & 0 & 0 & 0 & 89.13 \\
\hline 21 & 0 & 0 & 0 & 87.83 \\
\hline 22 & 0 & 0 & 0 & 88.06 \\
\hline 23 & 0 & 0 & 0 & 89.18 \\
\hline
\end{tabular}
each factor.

TABLE II. EXPERIENCE DESIGNS AND RESULTS

The regression equation (2) is used to analyze the regression equation of the sweep rate coding space, as shown in Table III. Test result shows that the regression model, the fitting variance was not significant, the regression equations and the measured value, the appropriate regression model; test index cleaning rate of regression model, the regression equation shows that cleaning rate is extremely significant in the level, the mathematical model and test data is used for the match.

TABLE III. VARIANCE ANALYSIS OF MODEL

\begin{tabular}{lllll}
\hline \multirow{2}{*}{$\begin{array}{l}\text { Variation } \\
\text { source }\end{array}$} & \multicolumn{4}{l}{ Cleanliness rate(\%) } \\
\cline { 2 - 5 } & $\begin{array}{l}\text { Sum of } \\
\text { squares }\end{array}$ & df & $\begin{array}{l}\text { Mean } \\
\text { square }\end{array}$ & F value \\
\hline Model & 100.11 & 9 & 11.12 & F2=22.77 \\
\hline Residual & 6.35 & 13 & 0.49 & \\
Lack of fit & 3.50 & 5 & 0.70 & F1=1.97 \\
Pure error & 2.85 & 8 & 0.36 & \\
Cor total & 106.46 & 22 & & \\
\hline
\end{tabular}

The $\mathrm{F}$ regression was used to identify the regression coefficients in the cleaning rate, and the median coefficient of confidence was below the following non significant coefficients.
A simplified regression model of cleaning rate was obtained, as shown in formula 3.

$$
y_{1}=88.35-0.46 X_{1}+0.77 X_{2}+2.28 X_{3}+0.38 X_{1}^{2}-0.80 X_{2}^{2}-0.73 X_{2} X_{3}
$$

2) The performance indexes were analyzed by various factors:

By analysis, the contribution rate of each factor to the performance index cleaning rate is [20] as shown in Table IV. The results of Table IV show that the contribution rate of each factor to sweep rate is rolling brush speed, disc brush speed and running speed in turn. The most important factor is rolling brush speed, and the speed of disc brush is less, and the speed of

\begin{tabular}{|c|c|c|c|c|}
\hline \multirow{2}{*}{$\begin{array}{c}\text { perfor } \\
\text { mance } \\
\text { index }\end{array}$} & \multicolumn{3}{|c|}{$\begin{array}{l}\text { Contribution rate of } \\
\text { influential factors }\end{array}$} & \multirow{2}{*}{$\begin{array}{c}\text { Ranking of } \\
\text { contribution } \\
\text { rate }\end{array}$} \\
\hline & $\mathbf{x}_{1}$ & $\mathbf{X}_{2}$ & $\mathbf{X}_{3}$ & \\
\hline$\hat{y}_{1}$ & 0 & 0.94 & 0.98 & $\mathrm{x}_{3}>\mathrm{x}_{2}>\mathrm{x}_{1}$ \\
\hline
\end{tabular}
driving is smaller.

TABLE IV. IMPORTANCE OF EFFECTS OF FACTORS ONRESPONSE FUNCTIONS

C. The Influence of Experimental Factors on Cleaning Performance was Analyzed

1) Single factor affects the sweep rate:

On the basis of formula (3), other factors were 0 level, and single factor analysis was carried out. The influence models of the driving speed, the speed of the disk brush and the rotational speed of the brush on the cleaning rate are obtained, such as formula (4) (6).

$$
\begin{gathered}
y_{2}=88.35-0.46 X_{1}+0.38 X_{1}^{2} \\
y_{3}=88.35+0.77 X_{2}-0.80 X_{2}^{2} \\
y_{4}=88.35+2.28 X_{3}
\end{gathered}
$$

According to the influence equation of the single factor on the cleaning rate, the influence curve of each factor on the test index is obtained, as shown in Figure III.

Figure III Effect of single factor on cleaning rate Figure IV Effect of single factor on We can see from Figure III, the small road cleaning machine, cleaning brush with the increase of speed rate increased significantly, the maximum cleaning rate occurs at the maximum speed, this is because the increased speed of the rolling brush can effectively improve the throwing height, so that garbage throwing more rubbish bins; with the increase of the rotational speed of the disc brush. Cleaning rate was first increased and then decreased trend in the level of $110 \mathrm{r} / \mathrm{min}$ reached the maximum value at the zero level; with the increase of speed, cleaning rate decreased gradually; the cleaning machine cleaning brush, disc brush speed is higher than the effect and speed of the cleaning rate, and obvious effect. The results of the analysis are in accordance with the test results of the pretest. 


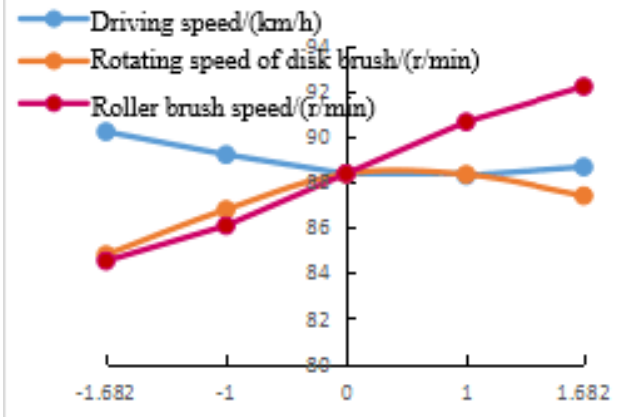

FIGURE III. EFFECT OF SINGLE FACTOR ON CLEARANCE RATE

2) The double factor affects the sweep rate:

For the established regression equation (2), one of the experimental factors is determined, one is speed of running, the speed of brush and speed of rolling brush, one is fixed at zero level, and the other two factors are studied. Design-expert is used to get the response surface of the interaction between the running speed and the brush speed, the running speed and the rolling brush speed, the speed of the disc brush and the speed of the rolling brush to sweep rate, as shown in Figure IV.

The effect of driving speed and disk speed on the cleaning rate are shown in Figure 4a. In the rolling brush speed zero level (130r/min), at the level of the $-1 \sim+1$ range, with the increase of vehicle velocity, cleaning machine cleaning rate was first slow downward trend with the increase of rotational speed of the disc brush; a slow downward trend, but there is no obvious change, that changes driving speed and rotating speed of disc brush interaction small influence on the cleaning rate.

The effect of driving speed and roll speed on the cleaning rate are shown in Figure IV B. When the disk brush speed is zero $(110 \mathrm{r} / \mathrm{min})$, with the increase of rolling brush speed, the sweep rate is increasing. With the increase of driving speed, the cleaning rate is not changed slowly. The influence of roller brush speed on the sweep rate is higher than that of driving speed.

The influence of the rotating speed of the brush and the rotational speed of the brush on the cleaning rate are shown in Figure IV C. We can see from Figure IV, when the cleaning speed zero level $\left(5 \mathrm{~km}, \mathrm{~h}^{-1}\right)$, disc brush speed and roller speed interaction on the road cleaning rate to a convex surface, when the rolling brush speed, road sweeping rating with the increase of broom rotate speed increased first and then decreased; when the disc brush and when the rotating speed, road sweeping rate decreases with the increasing speed of the rolling brush and increased gradually. Rolling brush cleaning rate higher than the effect of speed on the disc brush speed, when the roller speed is $148 \mathrm{R}-\mathrm{min}^{-1}, \mathrm{R}$ - disc brush speed of $110 \mathrm{~min}^{-1}$, cleaning rate $91.56 \%$.
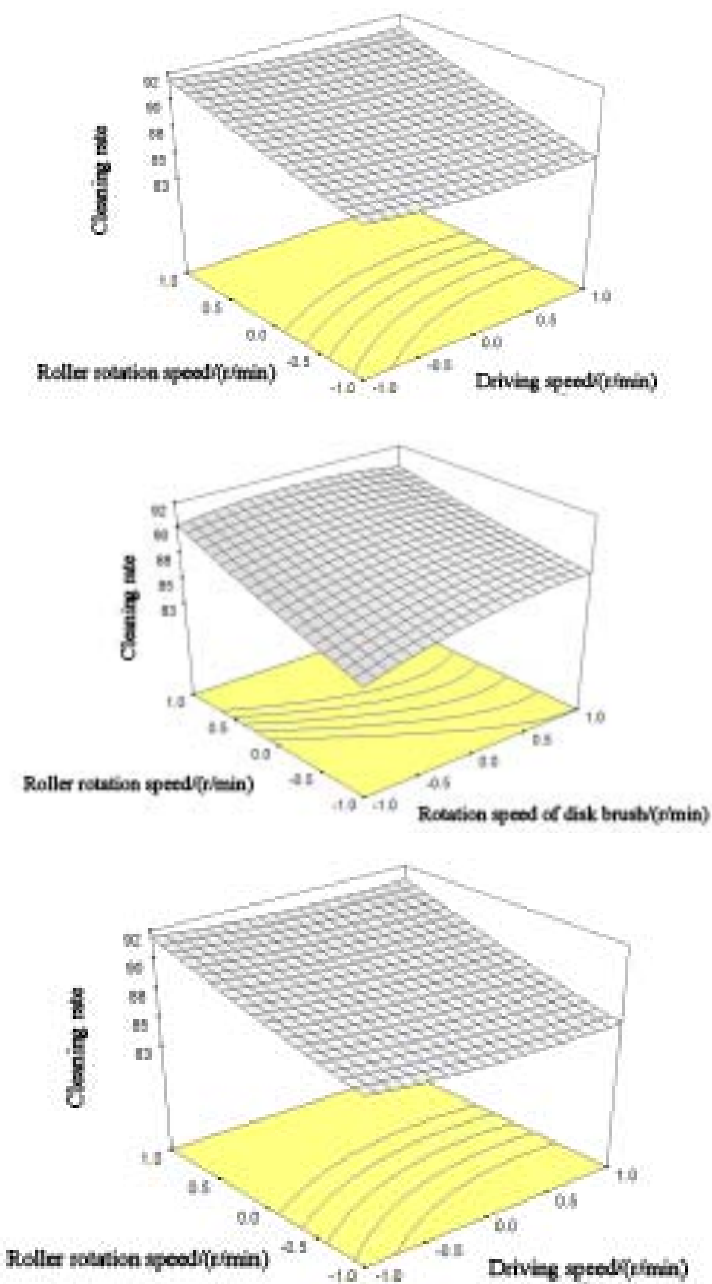

FIGURE IV. THE RESPONSE SURFACE OF VARIOUS FACTORS TO CLEARANCE RATE

\section{Parameter Optimization and Experimental Verification}

\section{1) Parameter optimization:}

In order to get the best level of test factors, and to meet the requirement of road cleaning performance, the maximum cleaning rate is the objective function, and the experimental factors are optimized. A mathematical model is established by taking the result of the cleaning performance test factor as a constraint condition.

$$
\begin{gathered}
\max y_{1}\left(X_{1}, X_{2}, X_{3}\right) \\
-1.682 \leq X_{1} \leq 0 \\
-1 \leq X_{2} \leq 1 \\
0 \leq X_{3} \leq 1
\end{gathered}
$$

The use of Design Expert 6.0.10, the parameter optimization, 
can satisfy the performance requirements of the cleaning, the cleaning rate of optimized parameters: the maximum speed of $5 \mathrm{~km}$, cleaning $\mathrm{H}-1,105 \sim 115 \mathrm{R}, \mathrm{min}^{-1}$ speed disc brush, roller brush speed 146 148 R, min $^{-1}$, road sweeping rate reached $91 \%$.

\section{2) Experimental verification:}

The best combination of parameters obtained by analysis is not included in the test scheme, and the verification test is needed to make further analysis[21].

The test scheme and results are shown in Table V. The results of 5 repeated tests show that the average road cleaning rate is $(92.15+0.47) \%$.

\section{TABLE V. VALIDATION OF TEST RESULT}

\begin{tabular}{llll}
\hline $\begin{array}{l}\text { Sweep } \\
\text { speed } \\
\left(\mathbf{k m} \cdot \mathbf{h}^{-1}\right)\end{array}$ & $\begin{array}{l}\text { Spray } \\
\text { brush } \\
\text { speed } \\
\left(\mathbf{r} \cdot \mathbf{m i n}^{-1}\right)\end{array}$ & $\begin{array}{l}\text { Rolling } \\
\text { speed } \\
\left(\mathbf{r} \cdot \mathbf{m i n}^{-\mathbf{1}}\right)\end{array}$ & $\begin{array}{l}\text { Average } \\
\text { Clearance rate } \\
/ \%\end{array}$ \\
\hline 5 & 110 & 148 & $92.15 \pm 0.47$ \\
\hline
\end{tabular}

Considering the car cleaning power consumption and mileage requirements, driving speed of $5 \mathrm{~km}, \mathrm{H}-1,105 \sim 110$, R disc brush speed $\mathrm{min}^{-1}$, brush speed of 146 148 $\mathrm{R}, \mathrm{min}^{-1}$, cleaning the best cleaning rate of $92 \%$, to meet the cleaning requirements, consistent with the theoretical results of optimization[22].

\section{CONCLUSION}

- After research and developing the cleaning system of the small road cleaning machine has carried on the single factor and orthogonal experiment research, analysis the primary and secondary factors which affected the sweeping efficiency of the road followed by disk brushes roller speed, disc brush speed, driving speed.

- Through the responsing surface analysis, disc brush speed X2and roller speed X3 interaction has obviously effect on the sweeping efficiency of the road, it is conclude-d that when the roller speed doesn't change, the sweeping efficiency of the road will b-e first increased and then go down by the speed of the disc brush. When disc brush speed doesn't change, the sweeping efficiency of the road will be first increased by the disc brush speed. Interaction in the disc brush speed and roller speed, roller speed are the main factors influenced the sweeping efficiency of the road, cleaning the speed o-f $5 \mathrm{~km} / \mathrm{h}$, when the roller speed is 147.84 $\mathrm{r} / \mathrm{min}$, disc brush speed is $109.36 \mathrm{r} / \mathrm{min}$. The weeping efficiency of the road reached $91.56 \%$.

- Use the constraint function parameter optimization function of Design Expert 6.0.10, the sweeping efficiency of the road as evaluation indexes, optimal solution of the regression model of the sweeping efficiency of the road, it is concluded that the best parameter combination for the cleaning speed of $5.27 \mathrm{~km} / \mathrm{h}$, disc brush speed $106.85 \mathrm{r} / \mathrm{min}$, the roller speed is $159.86 \mathrm{r} / \mathrm{min}$, road QingSaoLv was $92.81 \%$, and after the test verification, gets the average rate is $92.15 \%$.

\section{REFERENCES}

[1] Yun X U, Xin-Feng L I, Xiao T Y, et al. Research on Applications of computational dynamic fluid in the Simulation Analysis of Highway Mechanical Sweeper[J]. Acta Simulata Systematica Sinica, 2004.

[2] Blehert M L, Sampson W J. Combined sweeper and scrubber[J]. 1992.

[3] Pollack J W, Knowlton C M. High dump floor scrubber sweeper[J]. 2017.

[4] Martin E. Scrub water heating system for floor cleaner[J]. 2014.

[5] Zhang D Q, Su C Q, Ou Y H. Simulation and optimization of the suction system of vacuum sweeper with a front-mounting dust collection box[J]. Mechanical Research \& Application, 2009.

[6] Chen Z J, Xiao-Yuan W U, Guang-Pu X U, et al. Experimental Study on Suction Mouth of Vacuum Sweeper[J]. Journal of Tongji University, 2001.

[7] Zhu F L, Zhang G Z, Chen J. Flow field analysis and structure optimization of vacuum sweeper suction mouth[J]. Machinery Design \& Manufacture, 2008.

[8] Pant B R. Ground water quality in the Kathmandu valley of Nepal[J]. Environmental Monitoring \& Assessment, 2011, 178(1-4):477.

[9] Conrad W E. Configuration of a motor housing for a surface cleaning apparatus[J]. 2010.

[10] Conrad W E. Suction motor and fan assembly housing construction for a surface cleaning apparatus[J]. 2013.

[11] Conrad W E. Cyclone chamber construction for a surface cleaning apparatus[J]. 2014.

[12] Taneda Y. Dry type cleaning housing and dry type cleaning apparatus[J]. 2016.

[13] Corporation E. Plating apparatus and cleaning device used in the plating apparatus[J]. 2015.

[14] Mayer S T. Detection of plating on wafer holding apparatus[J]. 2017.

[15] Shrestha S, Semkuyu D J, Pandey V P. Assessment of groundwater vulnerability and risk to pollution in Kathmandu Valley, Nepal[J]. Science of the Total Environment, 2016, 556:23-35.

[16] Gordon J D. Flash vortex brush device and method[J]. 2016.

[17] Shrestha S, Nakamura T, Malla R, et al. Seasonal variation in the microbial quality of shallow groundwater in the Kathmandu Valley, Nepal[J]. Water Science \& Technology Water Supply, 2014, 14(3):390.

[18] Xin Y H, Li H, Wu J J. Applications of CFD Technique in the Flow Field Analysis of Road Sweeper[J]. Applied Mechanics \& Materials, 2015, 733:583-586.

[19] Zeng G Y, Xin-Feng L I, Xiao T Y, et al. Simulation for the Design of Dust Suction System of Highway Sweeper[J]. Acta Simulata Systematica Sinica, 2004, 16(12):2770-2773.

[20] Liu B, Liu Q. Parameters Optimization of Negative Pressure Suction Type Atomization Device and Dust Fall Experiment Study[J]. Safety in Coal Mines, 2017.

[21] Hui-Chao X U, Zhao-Qin L V. Design and Simulation for a New Cleaning Sweeper[J]. Journal of Shandong Agricultural University, 2016.

[22] Mohammadi A, Erfanian A R, Mosavi M R, et al. Design and Simulation a New Unique-Slit Reticle for Pulsed Infrared Seekers[J]. Journal of the Optical Society of Korea, 2014, 18(1):1-8. 